\title{
C- AND N-STABLE ISOTOPE CHARACTERICS OF DIAMONDS FROM NAMIBIA.
}

\author{
Pierre Cartigny $^{1}$, Thomas Stachel ${ }^{2,3}$, Jeff. W. Harris ${ }^{4}$ and Marc Javoy ${ }^{1}$ \\ ${ }^{l}$ Institut de Physique du Globe de Paris, France; ${ }^{2}$ University of Alberta, Edmonton, Canada; \\ ${ }^{3}$ University of Frankfurt, Germany; ${ }^{4}$ University of Glasgow, Scotland, United-Kingdom.
}

\section{INTRODUCTION}

The work undertaken on 106 inclusion-bearing diamonds from the placer deposits of Namibia (see Loest et al., 2003, this issue) revealed the presence of a previously unidentified paragenesis (referred to as "undetermined", $\mathrm{n}=13$ ). The undetermined suite of inclusions is characterised by (1) unusual textural features such as exsolution of orthopyroxene from clinopyroxene (2) in part, low Mg-values and high $\mathrm{K}$, $\mathrm{Ba}, \mathrm{Sr}$ and (3) the presence of rather unusual inclusions such as $\mathrm{Mg}$ - and $\mathrm{Ca}-\mathrm{CO}_{3}$, a Ti-rich phase, phlogopite and coesite.

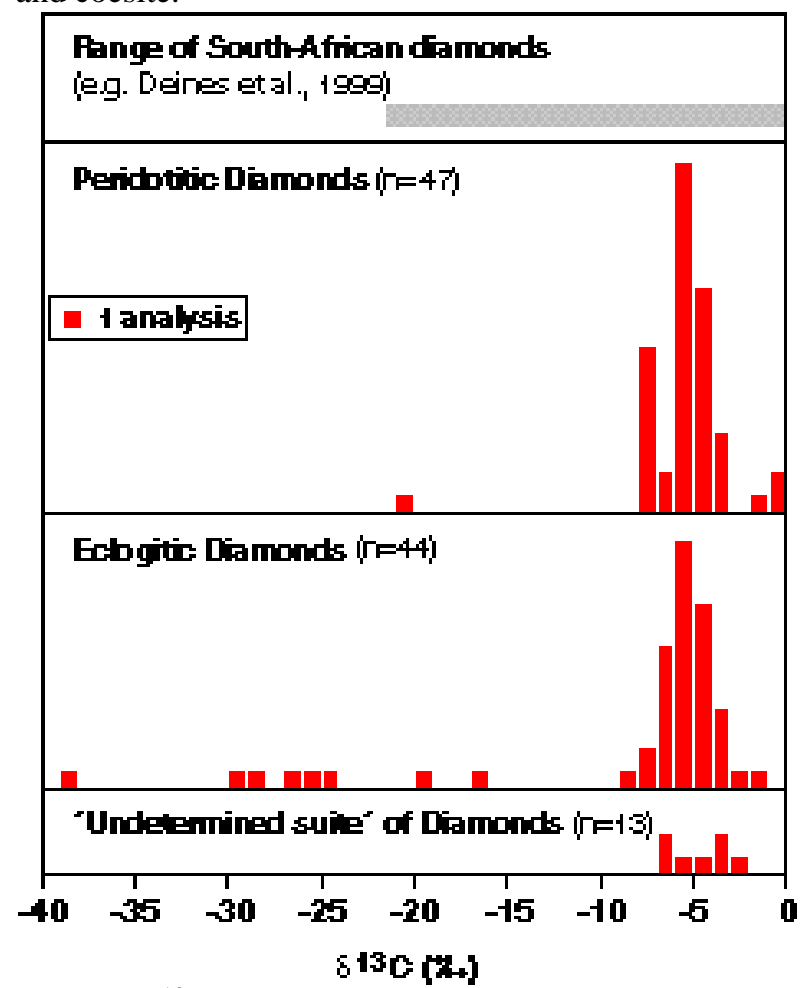

Figure 1: $\delta^{13} \mathrm{C}$ distributions of Namibian diamonds. Note that eclogitic diamonds extend the known diamond $\delta{ }^{13} \mathrm{C}$ range down to $-38.5 \%$ and clearly exceed the $\delta^{13} \mathrm{C}$ range known for South-African kimberlites.

The crystallisation of the "undetermined suite" of inclusions and their host diamonds occurred at rather high $\mathrm{T}\left(1300-1500^{\circ} \mathrm{C}\right)$ and $\mathrm{P}(60-70 \mathrm{kbar})$. As typified by the unusual chemical and mineralogical features, the inclusions and their host diamonds likely result from the interaction of mantle peridotites or opx-bearing eclogites (websterites) with carbonate rich fluid (Loest et al., 2003).

It is the aim of the present work to characterise C- and $\mathrm{N}$-stable isotopes, $\mathrm{N}$-contents and aggregation levels for diamonds of the undetermined paragenesis to better constrain the origin (i.e. mantle- vs subduction-related) of the carbonate-rich metasomatic agent associated with diamond formation.

As diamonds from Namibia have not been previously studied in detail, in addition to the "undetermined" group, we also provide carbon and nitrogen isotopic data for peridotitic $(n=49)$ and eclogitic $(n=43+1$ normal websteritic) diamonds from this region. As a consequence, the present results, also allow a comparison to be made with previously studied diamonds from South-African kimberlites.

\section{METHODS}

From all the broken fragments and powder, two diamond chips from each sample was chosen, weighting between 0.15 to 2.30 milligrams. The first fragment of each diamond was combusted and analysed for $\delta^{13} \mathrm{C}$ yielding the $\delta^{13} \mathrm{C}$-distribution presented in Figure 1. In order to determine the nitrogen content and aggregation state, the second fragment of each diamond was analysed by FTIR spectroscopy. On the basis of its paragenesis, $\delta^{13} \mathrm{C}$ and $\mathrm{N}_{\mathrm{FTIR}}$-contents, 41 diamonds, so far, have been selected and combusted for simultaneous determination of $\delta^{13} \mathrm{C}-\delta^{15} \mathrm{~N}$ and $\mathrm{N}$-content $\left(\mathrm{N}_{\text {Bulk }}\right.$ Combustion $=\mathrm{N}_{\mathrm{BC}}$ ).

\section{RESULTS}

As illustrated by Figure 1, diamonds from Namibia cover a large range of $\delta^{13} \mathrm{C}$-values. Peridotitic diamonds range from -20.3 to $-0.5 \%$ and eclogitic diamonds from -38.5 to $-1.6 \%$. The undetermined suite spans a narrower $\delta^{13} \mathrm{C}$-range from -8.5 to $-2.7 \%$. 

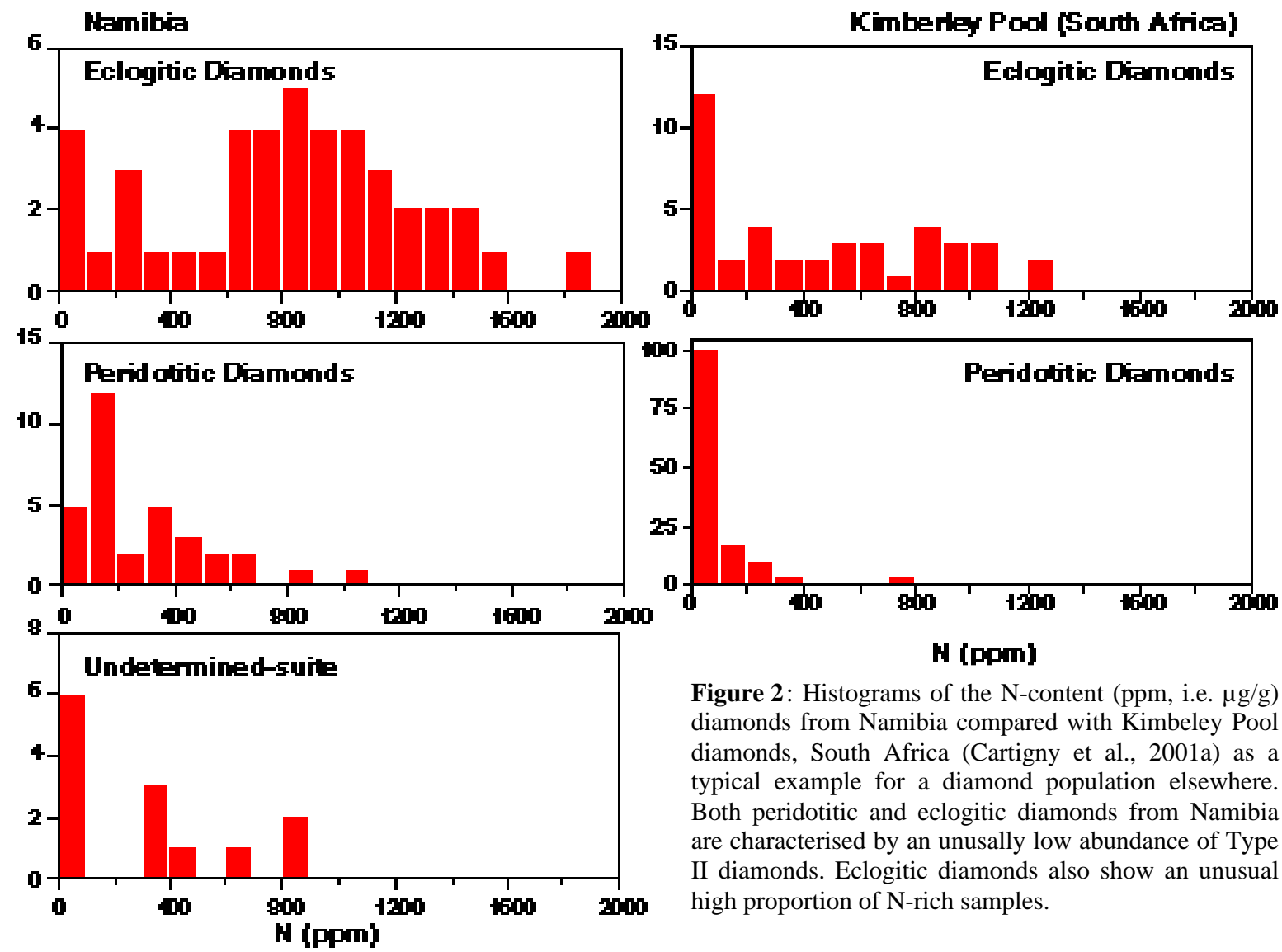

Figure 2: Histograms of the N-content (ppm, i.e. $\mu \mathrm{g} / \mathrm{g}$ ) diamonds from Namibia compared with Kimbeley Pool diamonds, South Africa (Cartigny et al., 2001a) as a typical example for a diamond population elsewhere. Both peridotitic and eclogitic diamonds from Namibia are characterised by an unusally low abundance of Type II diamonds. Eclogitic diamonds also show an unusual high proportion of $\mathrm{N}$-rich samples.

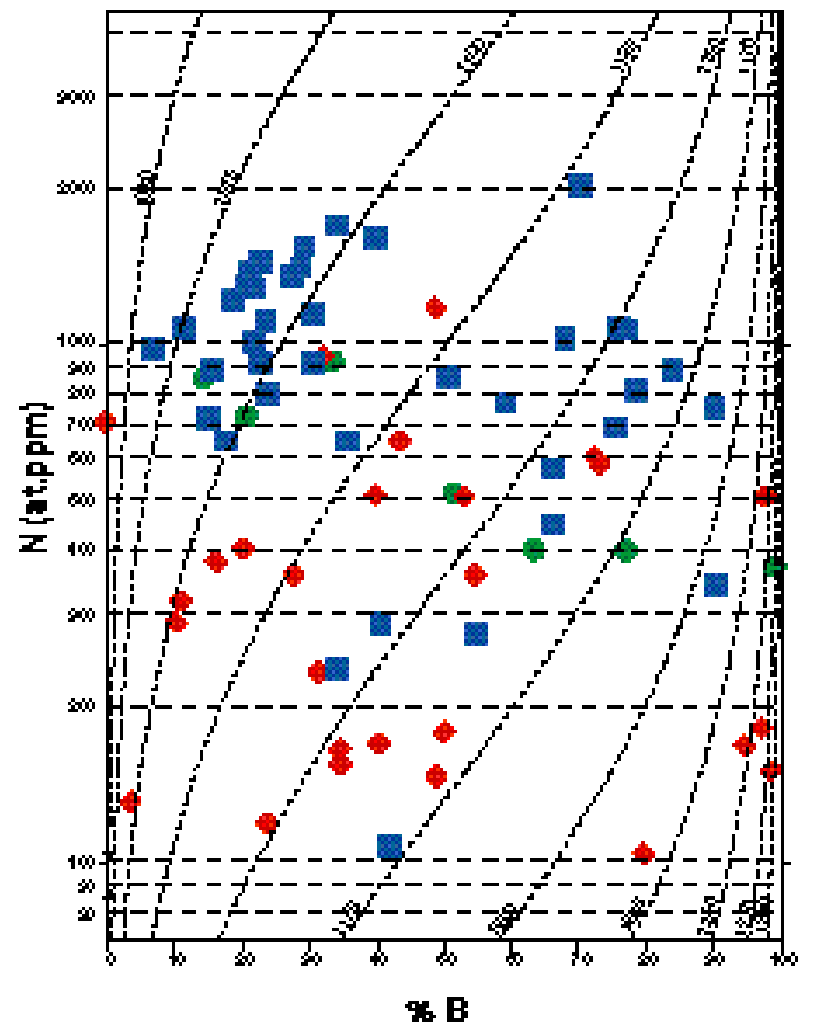

Nitrogen contents range from 0 (i.e. Type II) to 1090 ppm (i.e. $\mu \mathrm{g} / \mathrm{g}$ ) in peridotitic diamonds and from 0 up to $1860 \mathrm{ppm}$ in eclogitic diamonds. Diamonds belonging to the "undetermined suite" show $\mathrm{N}$-contents ranging from 0 to $875 \mathrm{ppm}$. When compared with previous studies, diamonds from Namibia are characterised by an unusually low proportion of peridotitic and eclogitic Type II diamonds and an unusually high proportion of N-rich (e.g. > 600 ppm) diamonds. Nitrogen aggregation states vary from IaA (N-pairs) to IaB (clusters of four $\mathrm{N}$-atoms) diamonds, with no clear relation to either paragenesis or N-contents (Figure 3).

Figure 3: Relationships of nitrogen aggregation state with total nitrogen content (as determined by FTIR). Red diamonds denote peridotitic, blue squares eclogitic and green circles diamonds from the "undetermined suite". Time integrated isotherms (dashed lines) are reconstructed for a mantle residence time of $1 \mathrm{Ga}$. 


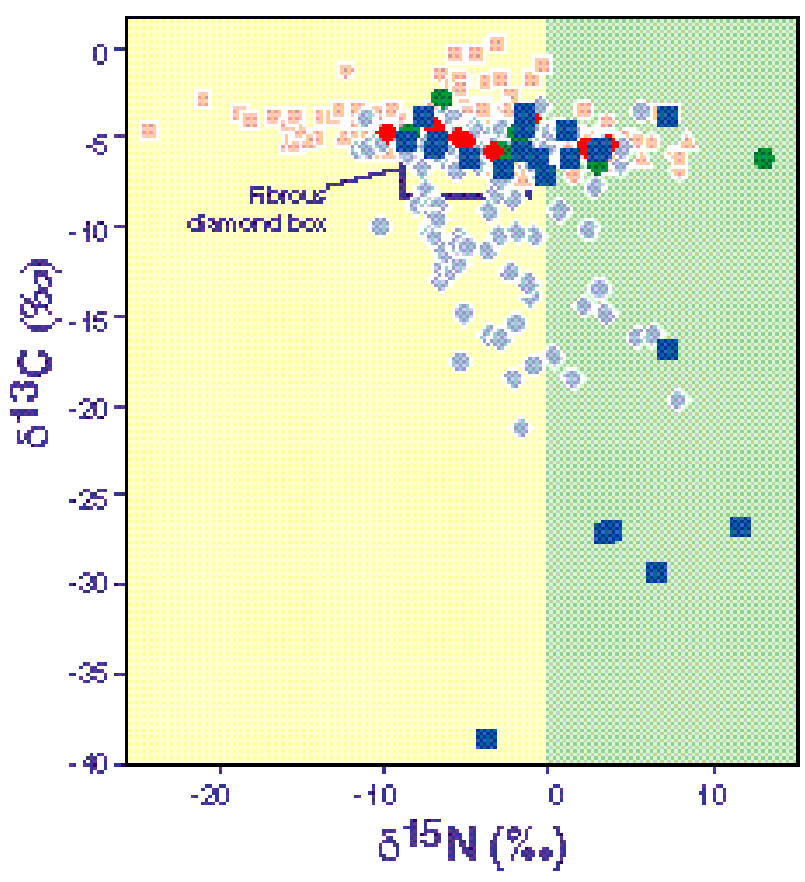

Figure 4: $\delta^{13} \mathrm{C}-\delta^{15} \mathrm{~N}$ diagram for diamonds from Namibia (same symbols as Figure 3). Light red and light blue points correspond to published analyses of peridotitic and eclogitic diamonds worldwide.

The forty-one diamonds combusted for $\delta^{13} \mathrm{C}, \delta^{15} \mathrm{~N}$ and $\mathrm{N}$-content measurements, included 9 peridotitic, 23 eclogitic and 9 diamonds from the undetermined suite. Four samples with unusually low $\mathrm{N}$-contents have been analysed with an improved procedure developed recently and results will be duplicated before the conference.

Peridotitic diamonds have $\delta^{15} \mathrm{~N}$-values ranging from -9.8 up to $+3.7 \%$ with no obvious relationship with $\delta^{13} \mathrm{C}$-values (from -5.7 to $-3.7 \%$; Figure 4 ) or $\mathrm{N}$ contents (60 to $750 \mathrm{ppm}, \mathrm{BC}$ ); a situation somewhat similar to previously analysed peridotitic diamonds (e.g. Cartigny et al., 1997). However, in contrast to the study on Kimberley Pool which suggested that peridotitic diamonds with the highest $\mathrm{N}$-contents have only negative $\delta^{15} \mathrm{~N}$-values, peridotitic diamonds from Namibia with the highest N-content (750 ppm) also show the highest $\delta^{15} \mathrm{~N}$-value (i.e. $+3.7 \%$ ).

Eclogitic diamonds have $\delta^{15} \mathrm{~N}$-values ranging from -8.5 up to $+11.8 \%$ o. Diamonds from this suite with $\delta^{13} \mathrm{C}$ of $-5.0 \pm 1.5 \%$, (Figure 4), are associated with a large range of $\delta^{15} \mathrm{~N}(-8.9$ to $+7.2 \%$ ) and do not appear to be related to total $\mathrm{N}$-content, (but data so far are limited to high $\mathrm{N}$-contents). Again, high $\mathrm{N}$-contents are associated with positive $\delta^{15} \mathrm{~N}$-values. Eclogitic diamonds with $\delta^{13} \mathrm{C}$-values between -16 and $-10 \%$ also show positive $\delta^{15} \mathrm{~N}$-values, but the lowest $\delta^{13} \mathrm{C}$-value is associated with a negative $\delta^{15} \mathrm{~N}$-value of about $-3 \%$ (Figure 4 ).

Of the nine samples of the "undetermined paragenesis", only six gave $\delta^{15} \mathrm{~N}$-values, the other three having too low $\mathrm{N}$-contents. The $\delta^{15} \mathrm{~N}$-values range from -8.3 to $+13.2 \%$ and, again, no variations with $\delta^{13} \mathrm{C}$ or $\mathrm{N}$ contents are observed. However, in this limited dataset, the lowest $\delta^{15} \mathrm{~N}$-values are restricted to samples having the highest $\mathrm{N}$-contents.

Overall, the comparison of $\delta^{13} \mathrm{C}$-values measured on two different parts of a single crystal (Fig. 5), shows good isotopic homogeneity (variability $<2 \%$ ). In one case, however, a peridotitic sample gave a $\delta^{13} \mathrm{C}$ range of $15.4 \%$ (the red points, inset of Figure 5). Such an internal $\delta^{13} \mathrm{C}$-variation is rare, but has previously been found for Jagersfontain and Kimberley Pool diamonds, (Deines et al, 1991). The comparison of N-contents measured on the same fragment by combustion and FTIR, shows good homogeneity (Figure 5).

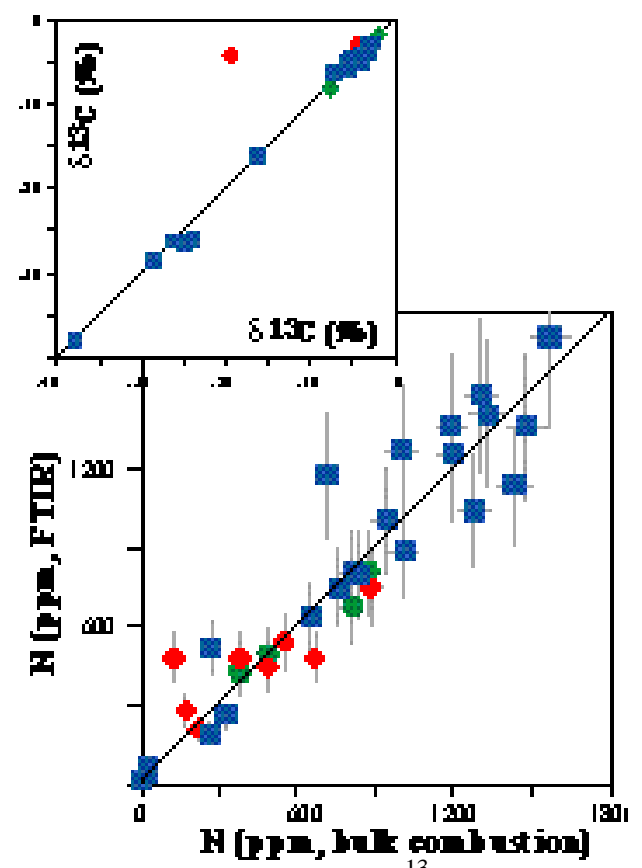

Figure 5: Comparison of $\delta^{13} \mathrm{C}$-values measured on two diamond chips from the same crystal and $\mathrm{N}$-contents as determined by FTIR and bulk combustion on the same fragment.

\section{DISCUSSION}

The $\delta^{13} \mathrm{C}$-value of $-38.5 \%$ measured in one Namibian sample is the lowest observed for a diamond so far and the high $\delta^{15} \mathrm{~N}$-value of $+13.2 \%$ measured in a sample of the "undetermined paragenesis" is distinctly higher than values measured in previous studies. However, these results represent extreme values, and overall, the 
suite when compared with peridotitic or eclogitic diamonds from other cratons (including Slave, Kaapvaal, Sino-Korean and Western African), diamonds from Namibia (including peridotitic and eclogitic) are primarily characterised by exceptionally high N-contents (Figure 2).

This high level of nitrogen changes a number of current concepts. For example, one would expect that 5 of the 6 eclogitic Namibian diamonds with $\delta^{13} \mathrm{C}$-values $<-10 \%$ o would define the end-member of a trend of decreasing $\delta^{13} \mathrm{C}$ with increasing $\delta^{15} \mathrm{~N}$, these changes being associated with low nitrogen content (Cartigny et al., 2001a). Whilst the carbon and nitrogen isotopic evidence conform to this prediction, these five eclogitic diamonds have nitrogen contents up to $2100 \mathrm{ppm}$, which contrasts with the $<100$ ppm of eclogitic diamonds with similar $\delta^{13} \mathrm{C}$ values from other locations (data from Orapa and Jwaneng).

Also, the fact that Namibian peridotitic and eclogitic diamonds both have high $\mathrm{N}$-contents and positive $\delta^{15} \mathrm{~N}$ -values contrasts with previous published data (which would predict positive $\delta^{15} \mathrm{~N}$ only with low $\mathrm{N}$-contents). Thus the proposal that stable $\mathrm{C}$ - and $\mathrm{N}$-isotopic variations result from fractionation in the mantle as indicated from eclogitic and peridotitic diamonds from Orapa, Jwaneng or Kimberley Pool (see Cartigny et al., 2001a and references therein) does not extend to the present dataset. These results raise the question as to whether or not the eclogitic diamonds from Namibia are subduction-related.

In this respect, nitrogen is of prime interest as it shows a significant isotopic difference between sediments and the mantle. Both cover a large $\delta^{15} \mathrm{~N}$ range but the surface has mean positive $\delta^{15} \mathrm{~N}$ whereas the mantle shows distinctly mean negative $\delta^{15} \mathrm{~N}$. Contrasting, with the recent statement of Fischer et al. (2002), a significant proportion of the nitrogen is lost during subduction and transfered back to the surface via arcvolcanism, but not all. Nitrogen is actually efficiently recyled into the mantle as evidenced, e.g. by subduction-related microdiamonds formed in ultra-high pressure metamorphic rocks from the Kokchetav massif which contain up to 11000 ppmN (Cartigny et al., 2001b). Nitrogen isotopes can thus be used as efficient tracers of recycled-material.

The fact that most eclogitic diamonds show negative $\delta^{15} \mathrm{~N}$-values (including the lowest $\delta^{13} \mathrm{C}$-diamond) implies a strong mantle component and argues against diamond formation directly from recycled metasedimentary carbon
Mixing relationships between a mantle (both $\delta^{15} \mathrm{~N}$ and $\delta^{13} \mathrm{C} \approx-5 \%$ ) and a hypothetical recycled endmember are not supported by the available $\delta^{15} \mathrm{~N}$ and $\delta^{13} \mathrm{C}$ and $\mathrm{N}$ content as no relationship can be identified. This will be verified in detail with additional data, including diamonds with lower N-contents.

The striking similarity in $\delta^{13} \mathrm{C}, \delta^{15} \mathrm{~N}, \mathrm{~N}$-content and aggregation state for most of the eclogitic, peridotitic and "undetermined suite" diamonds implies that these diamond populations are somehow related. Particularly, the N-rich character, cannot be regarded as a coincidence. Thus, peridotitic AND eclogitic are either both mantle- or subduction-related and it is not possible to consider the origin of their carbon separately, (i.e. mantle-related for peridotitic diamonds and subductionrelated for eclogitic diamonds).

A model calling for fractionation of $\mathrm{C}$ - and $\mathrm{N}$-isotopes in the mantle (e. g. see Cartigny et al., 2001a) contrasts with a line of arguments, mainly based on O-isotopes, which indicate that some eclogite nodules found in kimberlites (e.g. Jacob et al., 1994) but not all of them (see Barth et al., 2002) may represent recycled oceanic crust. A similar conclusion was reached by Chaussidon et al., (1987) and Farquhar et al., (2002) based on Sisotopes from sulfide inclusions in diamonds. This apparent inconsistency is resolved if diamond formation is associated with metasomatic episodes (Schulze et al., 1996). In such cases, the source of the carbon and nitrogen is introduced into the host rock (peridotite or eclogite) decoupling diamond chemistry from that of the silicates, oxides and sulfides in the eclogites. In this respect, the "undetermined" suite of diamonds, whose formation is likely to be associated with a $\mathrm{CO}_{2}$ (carbonate) rich input, supports the present model.

However, the detail of the relationship between the undetermined-paragenesis diamonds with peridotitic and/or eclogitic diamonds is not yet fully understood. Geothermobarometry suggests the undetermined diamond suite crystallized at temperatures between $\left(1300-1500^{\circ} \mathrm{C}\right)$ which are much higher than those for normal peridotitic and eclogitic diamonds from Namibia (960 to $1300^{\circ} \mathrm{C}$, Loest et al.,- this volume). As nitrogen aggregation depends mainly on temperature and less on residence time, one might expect diamonds of the undetermined suite to display more advanced nitrogen aggregation states than eclogitic/peridotitic diamonds. This relationship is not seen in Figure 3. With the exception of the five low $\delta^{13} \mathrm{C}$-eclogitic diamonds, the data indicate a striking similarity in $\delta^{13} \mathrm{C}$ or $\delta^{15} \mathrm{~N}$ (Figure 4), suggesting a common origin. 
A further observation which can be made from Figure 3 , is that the geothermobarometry temperatures (1300$1500^{\circ} \mathrm{C}$ ), contrast with those determined from the nitrogen content and aggregation state systematics $\left(1100-1300^{\circ} \mathrm{C}\right.$ for a mantle residence time of about 1Ga). The difference of about $200^{\circ} \mathrm{C}$ suggests that diamonds of the undetermined suite may have mantle residence time much shorter than $1 \mathrm{Ga}$, but not related to the kimberlite magmatism, otherwise diamonds would probably be IaA (see Boyd et al., 1994). A more likely alternative is that diamonds originally formed in a hightemperature environment, reflected by the inclusion chemistries, which subsequently cooled by at least $200^{\circ} \mathrm{C}$ soon after inclusion encapsulation and diamond formation, thereby accounting for the exsolution of orthopyroxene from former homogeneous clinopyroxene (Loest et al., 2003).

\section{ACKNOWLEDGEMENTS}

Funding by the German Research Foundation (DFG) and French INSUE-CNRS is gratefully acknowledged. The Diamond Trading Company, a DeBeers Group Company, are thanked for kindly providing the specimens used in this study.

\section{REFERENCES}

Barth, M.G., et al., 2002. Geochemistry of xenolithic eclogites from West Africa, part 2: origins of the high $\mathrm{MgO}$ eclogites, Geochim. and Cosmochim. Acta 66, 4325-4345.

Boyd, S.R., Pineau, F. and Javoy, M., 1994. Modelling the growth of natural diamonds, Chem. Geol. 116: 29-42.

Cartigny, P., Boyd, S.R., Harris J.W. and Javoy, M. , 1997. Nitrogen isotopes in peridotitic diamonds from Fuxian, China : the mantle signature, Terra Nova, 9: 175-179.

Cartigny, P., Harris, J.W. and Javoy, M., 2001a. Diamond genesis, mantle fractionations and mantle nitrogen content : A study of $\delta^{13} \mathrm{C}-\mathrm{N}$ concentrations in diamonds. Earth Planet. Sci. Lett., 185: 85-98.

Cartigny, P., et al., 2001b. The origin and formation of metamorphic microdiamonds from the Kokchetav massif, Kazakhstan : A nitrogen and carbon isotopic study. Chem. Geol., 176: 267-283.

Chaussidon, M., Albarède, F. and Sheppard, S.M.F., 1987 Sulfur isotope heterogeneity in the mantle from ion microprobe measurements of sulphide inclusions in diamonds, Nature 330: 242-244.

Deines, P., Harris, J W, Gurney, J. J., 1991. The carbon isotopic composition and nitrogen content of lithospheric and asthenospheric diamonds from the
Jagersfontein and Koffiefontein Kimberlite, South Africa, Geochim. Cosmochim. Acta, 55: 2615-2625.

Deines P., Viljoen, F. and Harris, J. W., 1999 Implications of the carbon isotope and mineral inclusion record for the formation of diamonds in the mantle underlying a mobile belt; Venetia, South Africa. Geochim. Cosmochim. Acta, 65: 813-838.

Farquhar, J., et al.., 2002. Mass-independent sulfur of inclusions in diamond and sulfur recycling on early Earth, Science 298: 2369-2371.

Fischer

Jacob, D., Jagoutz, E., Lowry, D., Mattey, D. and Kudrajavtseva, G., 1994. Diamondiferous eclogites from Siberia: Remnants of Archean oceanic crust, Geochim. Cosmochim. Acta 58, 5191-5207.

Loest, I., Stachel, T., Brey, G.P., Harris, J.W. and Ryabchikov, I.D., 2003. Diamond formation and source carbonation: mineral associations in diamonds from Namibia. Contrib. Min. Petro. (in press).

Schulze, D.J., Wiese, D. and Steude, J., 1996. Abundance and distribution of diamonds in eclogite revealed by volume visualization of CT X-Ray scans. J. Geol. 104: 109-113.

Contact: P. Cartigny, Laboratoire de Géochimie des Isotopes Stables, Institut de Physique du Globe, 2 Place Jussieu, T5464 E1, 75251 Paris, Cedex 05, France.

E-mail:cartigny@ipgp.jussieu.fr 